\title{
Analysis of the Psychological State of Elderly People in the Process of Raising Plants from Seedlings and Bulbs by Means of Brain Waves and the Semantic Differential Technique - Including Comparison with Young People -
}

\author{
Sadako Norimatsu, Hiroshige NishinA*, Kayo NOZAKI* and Kotaro TAKAYAMA* \\ School of Medicine, Ehime University, Shitsukawa, Toon, Ehime 791-0295, Japan \\ * Faculty of Agriculture, Ehime University, Tarumi, Matsuyama, Ehime 790-8566, Japan
}

(Received May 21, 2007)

\begin{abstract}
In the present research, the psychological state of elderly people in the process of raising plants from seedlings and bulbs was analyzed by means of brain waves and the semantic differential technique. Subjects were ten elderly individuals and ten young individuals. Each subject raised four kinds of plants (hyacinth, pansy, Italian parsley and candelabra cactus) for ten weeks in his or her house. Subjects raised the hyacinth from bulbs and the pansy from seedlings. At the starting, second, sixth, and tenth weeks of the experiment, the psychological state of the subjects upon seeing their plants in front of them was evaluated. The ratio of alpha waves to beta waves was calculated as an index of the degree of calmness of psychological state. In the elderly subjects, the differences in the ratios of alpha waves to beta waves between the evaluated plants became smaller over time. The influence of the bloom of the pansy on the elderly subjects' psychological state was observed. An increase in the second factor score of the pansy evaluated by the elderly subjects was also observed and this indicated that the elderly people's psychological state was changed by the blooming process of the plants.
\end{abstract}

Keywords : bulb, elderly people, psychological state, raising plants, seedling

\section{INTRODUCTION}

"Green amenity" involves the indoor arrangement of houseplants and flowers as a means of making more comfortable use of interior space. Effects of green amenity include thermal environmental control, negative ion generation, air purification, alleviation and improvement of visual fatigue, and psychological relaxation (Asaumi et al., 1993; Asaumi et al., 1994; Asaumi et al., 1995a; Nishina et al., 1995; Nishina and Kawanishi, 1999; Nishina, 2000). The psychological effect is attributed to the relaxing effects of the indoor arrangement of houseplants on occupants (Asaumi et al., 1995b; Nishina et al., 1998; Nishina and Nakamoto, 1998).

Horticultural therapy has also attracted attention in recent years (Yoshinaga et al., 1998; Matsuo, 2000; Grosse, 2000) and has been implemented in medical, nursing, care, welfare, and other settings. The process of raising plants in horticultural therapy has been associated with psychological effects such as increased confidence, self-esteem, sense of fulfillment, satisfaction, hope, and happiness through attachment to the plant, in addition to recovery of physical functions. These

Corresponding author: Hiroshige Nishina, fax : +81-89-946-9916, e-mail : nishina@agr.ehime-u.ac.jp 


\section{S. NORIMATSU ET AL.}

effects may be particularly important for elderly individuals, who are at an increased risk for decline in physical and mental functions, as well as depression (Nakajima, 2005).

The authors have conducted research over the past 4 years on the psychological effects of raising plants on young individuals (Nishina and Nagayasu, 2002; Nishina and Gouda, 2004). This research involved psychological evaluation using measurements and analyses of electroencephalogram (EEG) that show the psychological state of subjects as determined by their involuntary reactions, in addition to the semantic differential (SD) technique (questionnaire), which is a method for evaluating subjective awareness (Iwashita, 1983; Funakoshi, 1987; Tsumita, 1987). During the past 2 years, we have also conducted research on elderly individuals, including their comparison to young individuals. In our previous study (Norimatsu et al., 2006), subjects were instructed to raise plants, including a cyclamen that was already blooming and a cactus that changed very little morphologically, at home for 10 weeks. The results showed that in comparison to young individuals, elderly individuals attained psychological stability from the process of raising plants, regardless of plant species.

In the present study, elderly individuals were asked to raise plants from seedlings and bulbs until they bloomed, and the psychological state of these individuals during the blooming process was analyzed by psychological evaluation using the aforementioned EEG measurement and analysis, as well as the SD technique. Analysis was also conducted for comparison with young individuals. Psychological analysis using physiological reactions such as EEG in addition to subjective evaluations such as the SD technique is commonly performed in the field of environmental psychology, which is the study of human psychological states under various environmental conditions (Yamazaki et al., 2003; Kato et al., 2004; Uchida et al., 2004).

\section{MATERIALS AND METHODS}

\section{Materials and experiment method}

The present study was conducted from October to December 2005. Subjects were 10 elderly individuals and 10 young individuals who had an interest in plants and consented to the study. Elderly subjects were 2 men and 8 women who had a mean age of 71.9 years (age range, 65-82 years). Young subjects were 4 men and 6 women who had a mean age of 21.1 years (age range, 20-24 years).

The following four plants species were used in the study: hyacinth (Hyacinthus orientalis), pansy (Viola $\times$ wittrockiana), Italian parsley (Petroselinum crispum $c v$., hereafter referred to as "parsley"), and candelabra cactus (Myrtillocactus geometrizans Console, hereafter referred to as "cactus"). Hyacinth was selected as a hydroponic plant to be raised from a bulb, pansy as a flowering plant to be raised from a seedling, parsley as a plant that could be eaten by the subjects upon maturation, and cactus as a plant that undergoes little morphological change.

The subjects were provided with all four plant species and instructed to arrange them in accessible locations at home and to water and look after them for 10 weeks. At a total of four time points, specifically the starting, second, sixth, and tenth weeks of the study, the subjects were taken by car to the Faculty of Agriculture, Ehime University with their plants. To create a familiar environment for the subjects, a room $(2.6 \times 3.4 \times 2.8 \mathrm{~m})$ partitioned by a curtain and resembling a home environment was set up in a seminar room (length, $5.9 \mathrm{~m}$; width, $3.4 \mathrm{~m}$; height, $2.8 \mathrm{~m}$ ) in the main building of the Faculty of Agriculture. The plants raised by each subject were individually placed in front of the subject inside the room and psychological evaluation was conducted using EEG and the SD technique.

The EEG measurement and analysis system consisted of an Electro-Cap (NEC San-ei Instruments, ECI), a control unit and amplifier (NEC, 6R12), and a computer with EEG analysis software (Kissei Comtec, ATAMAP). The Electro-Cap was equipped with electrodes according to 
the International 10-20 Electrode Placement System (20 electrodes on the scalp and 1 electrode on each ear lobe; total, 22 electrodes). The EEG measurement was conducted using referential derivation by linking both earlobe electrodes. In addition, electroconductive gel was injected between the scalp and electrodes for adhesion. The EEG measurement was performed in the following pattern: eyes open $70 \mathrm{~s} \rightarrow$ eyes closed $60 \mathrm{~s} \rightarrow$ eyes open $60 \mathrm{~s} \rightarrow$ eyes closed $50 \mathrm{~s}$. Although EEG measurements are usually taken with eyes closed, measurements with eyes open were also recorded in the present study, with the objective to analyze the psychological state of the subjects with the plants in view.

Following EEG measurements taken while viewing each plant, subjects were promptly transferred to another room for psychological evaluation using the SD technique. The SD technique is a method of attitude survey in which subjects grade their psychological reaction to target objects on a scale of adjective pairs (Iwashita, 1983; Funakoshi, 1987; Tsumita, 1987). Adjective pairs were selected from previous psychological, sensory, and related assessments based on their relevance to psychological states in the process of raising plants, rather than standard adjective pairs. The evaluation form in the present study comprised 22 adjective pairs on a 7-point scale (extremely, considerably, slightly, neither, slightly, considerably, and extremely).

In consideration of the possible tension of subject at the start of each measurement date, a preliminary EEG measurement using peperomia (Peperomia obtusifolia A. Dietr.) was conducted for each subject before the start of actual measurement on each measurement date. Data for peperomia were not included in the analysis. In addition, to eliminate the effects of the order of EEG measurement and psychological evaluation for the four plant species on the subjects' psychology, the order was changed for each subject.

\section{Analysis method}

The EEGs represent variations in electrical potential on the scalp that indicate the level of electrical activity in the brain. Alpha waves $\left(8.0^{-} 13.0 \mathrm{~Hz}\right)$ are associated with a mentally and physically relaxed state, while beta waves $\left(13.0^{-}-30.0 \mathrm{~Hz}\right)$ are associated with states of tension and excitement. As an indicator of comfort level, the $\alpha / \beta$ value was defined as the mean squared $\left(\mu \mathrm{V}^{2}\right)$ of $\alpha$ waves divided by the mean squared of $\beta$ waves; then the resulting value was further divided by the mean value of each subject for each measurement date. The use of the $\alpha / \beta$ value will correct any individual differences among subjects, as well as differences in physical conditions among different measurement dates for each subject. Large $\alpha / \beta$ values indicate a higher comfort level (a more relaxed state of mind), while smaller values indicate a low comfort level. Furthermore, since values for "the mean squared of $\alpha$ waves divided by the mean squared of $\beta$ waves" vary individually (roughly 5-20), its mean value for all subjects is likely to be greatly affected by any subjects with large mean values. Thus, to eliminate individual differences in "the mean squared of $\alpha$ waves divided by the mean squared of $\beta$ waves", the authors have traditionally obtained $\alpha / \beta$ values based on the above-mentioned procedure and performed analysis of comfort level using this $\alpha / \beta$ value (Nishina et al., 1998; Nishina and Nakamoto, 1998). No unified method for EEG analysis currently exists in the field of environmental psychology and researchers generally devise various methods to reduce individual differences in EEG (Yamazaki et al., 2003; Kato et al., 2004; Uchida et al., 2004).

Regarding measured data, data for the first $10 \mathrm{~s}$ of the second eyes-open phase (60 s) were excluded from analysis, and the mean data of ten data points $(2.56 \mathrm{~s}$ each) taken when the subjects were not blinking were analyzed. Blinking and closing of the eyes generate a myoelectric potential, which has a greater potential variation than EEG and thus creates noise in EEG analysis. Thus, to eliminate the effects of myoelectric potentials that may remain after opening of the eyes, data for the $10 \mathrm{~s}$ after eye opening were excluded from EEG analysis. In addition, because blink frequency varies individually from roughly 5 to $10 \mathrm{~s}$, and the EEG analysis time on the aforementioned EEG system can only be set to $2^{\mathrm{m}} / 10^{\mathrm{n}} \mathrm{s}$ (where $\mathrm{m}$ and $\mathrm{n}$ are integers), "data for the $2.56 \mathrm{~s}$ when the 


\section{S. NORIMATSU ET AL.}

subjects were not blinking" were analyzed. As for the SD technique, factorial analysis was performed for the evaluation data, and mean value profiles and distribution charts for factor scores were created.

\section{RESULTS AND DISCUSSION}

\section{Growth condition of plants}

The hyacinth, which was raised hydroponically from a bulb, showed almost no morphological changes other than growth of the root at around the second week. The pansy, which was raised from a seedling, developed buds at around the second week, bloomed at around the sixth week, and continued to bloom until the tenth week (Fig. 1). The parsley, which was raised from a seedling, showed little morphological change as subjects were instructed to tear off the leaves and eat them upon maturation. The cactus demonstrated no morphological changes during the 10-week study.

2. EEG analysis

Figure 2 shows the changes in the mean $\alpha / \beta$ value with eyes open in elderly subjects. The mean $\alpha / \beta$ value for the pansy, which had been low until the second week, became the highest of all four plant species after the sixth week. This change in $\alpha / \beta$ value appeared to correspond closely to the growth condition (blooming process) of the pansy. Differences in the mean $\alpha / \beta$ value between plant species were present at the starting week, but decreased by the tenth week. A paired t-test (for data obtained from the same individual) was performed for the mean (population mean) $\alpha / \beta$ values to investigate any significant differences between plant species. Significance level, which determines the significance of differences between plant species, was greater at the tenth week than at the starting week. Specifically, the following increases in significance level from the starting week to the tenth week were observed: hyacinth and pansy ( $4 \%$ to $66 \%$ ), hyacinth and parsley $(2 \%$ to $61 \%)$, pansy and cactus $(1 \%$ to $11 \%)$, and parsley and cactus $(1 \%$ to $13 \%)$. Thus, differences in the mean $\alpha / \beta$ value between certain species were present before the start of the growth process, but tended to disappear over time.

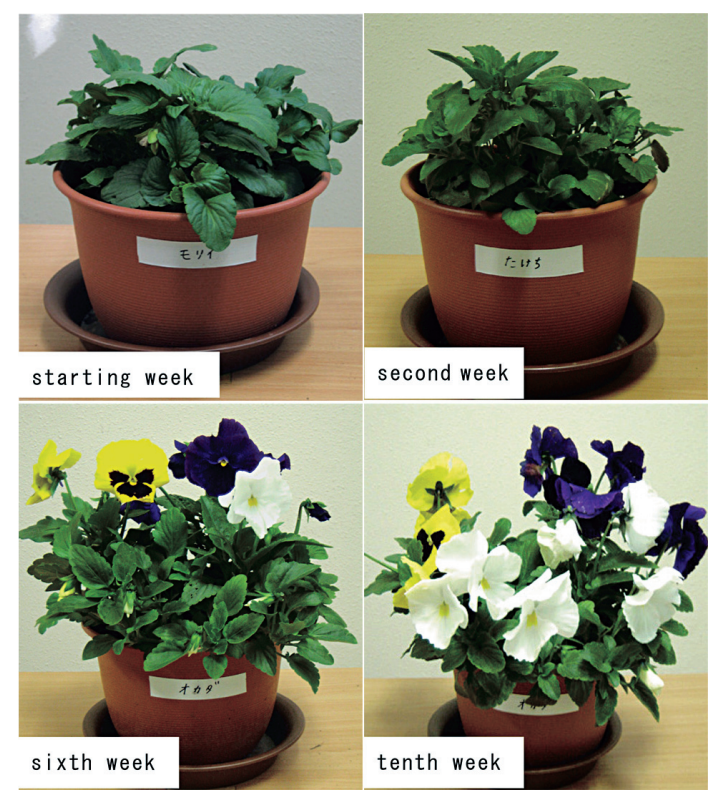

Fig. 1 Growing change of pansy. 


\section{PSYCHOLOGICAL EFFECT OF RAISING PLANT}

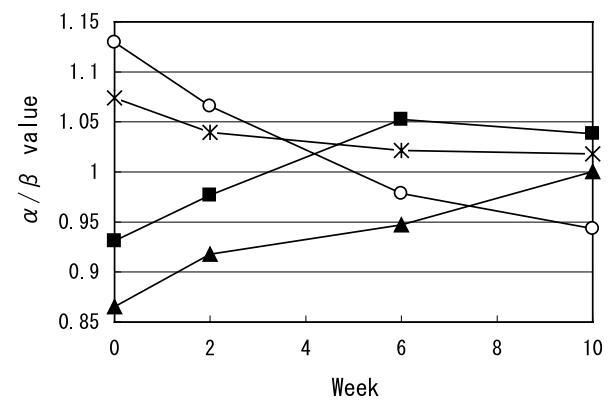

Fig. 2 Change in the average of the $\alpha / \beta$ value of elderly people with eyes open.

$*, \boldsymbol{\square}, \boldsymbol{\Delta}$, and $\bigcirc$ indicate hyacinth, pansy, parsley and cactus, respectively.

Figure 3 shows the changes in the mean $\alpha / \beta$ value with eyes open in young subjects. Although mean $\alpha / \beta$ values for the hyacinth decreased gradually from the starting week, the relative magnitudes for the mean values of other plant species were consistent throughout the 10 -week study. Although no significant differences in mean $\alpha / \beta$ value were observed between plant species at the starting week, large differences were observed at the tenth week. Significance level, which determines the significance of differences in mean $\alpha / \beta$ value between plant species, decreased from the starting week to the tenth week for the following: hyacinth and pansy ( $64 \%$ to $7 \%$ ), hyacinth and cactus ( $81 \%$ to $4 \%$ ), pansy and parsley ( $52 \%$ to $16 \%$ ), pansy and cactus $(90 \%$ to $42 \%)$, and parsley and cactus ( $36 \%$ to $5 \%)$. Thus, contrary to the findings for elderly subjects, the differences in mean $\alpha / \beta$ value between plant species increased over the course of plant growth for young subjects. The hyacinth, which was raised hydroponically, only developed a root at around the second week, and did not bloom as expected. Possibly due to this lack of growth, the mean $\alpha / \beta$ value decreased among young subjects, although almost no decreases were observed among elderly subjects.

These results showed that differences in mean $\alpha / \beta$ value between plant species decreased gradually over the 10 -week study among elderly subjects, indicating the disappearance of differences in psychological state with different plant species. It was thus surmised that the psychological state of elderly individuals was stabilized by the process of raising plants, and was not largely affected by the type of plant or changes in its morphology. Meanwhile, changes in the mean $\alpha / \beta$ value in elderly subjects for the pansy corresponded closely to its blooming process, thus suggesting that the psychological state of elderly individuals may change with changes in the plant's

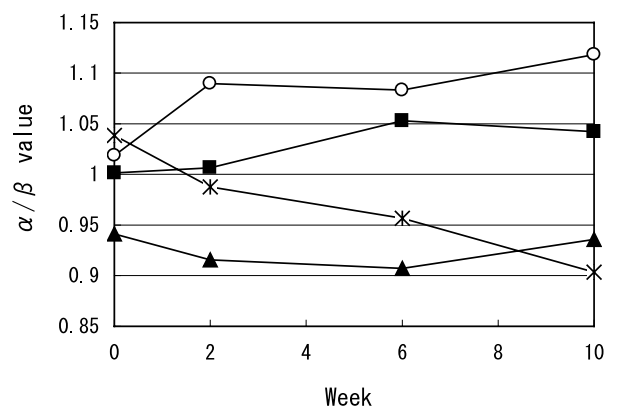

Fig. 3 Change in the average of the $\alpha / \beta$ value of young people with eyes open. The symbols ( $*, \mathbf{\square}, \mathbf{\Delta}$, and $\bigcirc$ ) are the same as those in Fig. 2. 


\section{S. NORIMATSU ET AL.}

growth condition (blooming process).

\section{Psychological evaluation using the SD technique}

Factor analysis of evaluation data identified a total of three factors. Table 1 shows the order of the first, second, and third factors based on results of the factor analysis, in addition to the factor loadings for the 22 pairs of adjectives, in order of the size of factor loading. The first factor included adjectives related to "mind relaxation", such as "Comforting" and "Calming", while the second factor included adjectives related to "visual attractiveness", such as "Stylish" and "Gorgeous". This finding may be attributable to the fact that pansies in the present study bore flowers of various colors (yellow, white, and purple) after the sixth week and thus affected the psychological state of both elderly and young subjects.

Figures 4 and 5 show the changes in mean value profile for the cactus in elderly and young subjects. The adjectives that were highly evaluated by subjects are listed on the right. In addition, the adjectives were listed with respect to the first and second factors, as well as in order of the size of factor loading. Although the cactus showed no changes in morphology during the 10-week study, values among young subjects gradually increased, mainly with regard to the first factor ("mind relaxation"). In contrast, values among elderly subjects changed very little during the 10week study.

Figures 6 and 7 show the changes in mean value profile for the hyacinth in elderly and young subjects. Although the hyacinth showed little morphological change after developing a root at around the second week, values among young subjects gradually increased, mainly with regard to the first factor. In contrast, elderly subjects showed relatively small changes. This result was the same as that for the cactus, a plant that did not undergo any morphological changes.

As for parsley, changes in mean value profile were small for both elderly and young subjects throughout the 10-week study. Although subjects were instructed to eat the parsley upon its maturation, the results suggested that the act of eating did not affect the subjects' psychological state.

Figure 8 shows the changes in mean value profile for pansy in elderly subjects. Possibly due to the fact that the pansy developed a bud at around the second week, and started to bloom at

Table 1 Construction of factors.

\begin{tabular}{c|c|cc}
\hline & First factor & Second factor & Third factor \\
\hline Pleasant & 0.882 & 0.322 & 0.151 \\
Bright & 0.869 & 0.371 & 0.162 \\
Lively & 0.868 & 0.358 & 0.172 \\
Pleasing & 0.856 & 0.358 & 0.288 \\
Comforting & 0.820 & 0.315 & 0.227 \\
Cozy & 0.817 & 0.352 & -0.008 \\
Refreshing & 0.817 & 0.306 & 0.230 \\
Natural & 0.801 & 0.467 & -0.168 \\
Pretty & 0.735 & 0.525 & 0.217 \\
Warm & 0.723 & 0.572 & 0.083 \\
Likable & 0.684 & 0.588 & 0.039 \\
Liberating & 0.675 & 0.235 & -0.219 \\
Calming & 0.671 & 0.037 & 0.099 \\
Dynamic & 0.509 & 0.458 & -0.307 \\
Stylish & 0.375 & 0.850 & 0.142 \\
Passionate & 0.261 & 0.800 & -0.152 \\
Gorgeous & 0.532 & 0.781 & -0.142 \\
Exciting & -0.001 & 0.720 & 0.554 \\
Variable & 0.503 & 0.618 & -0.425 \\
Moist & 0.414 & 0.525 & -0.026 \\
\cline { 1 - 1 } Balanced & 0.084 & -0.040 & 0.805 \\
Mild & 0.273 & -0.026 & 0.529 \\
\cline { 1 - 1 } & & &
\end{tabular}




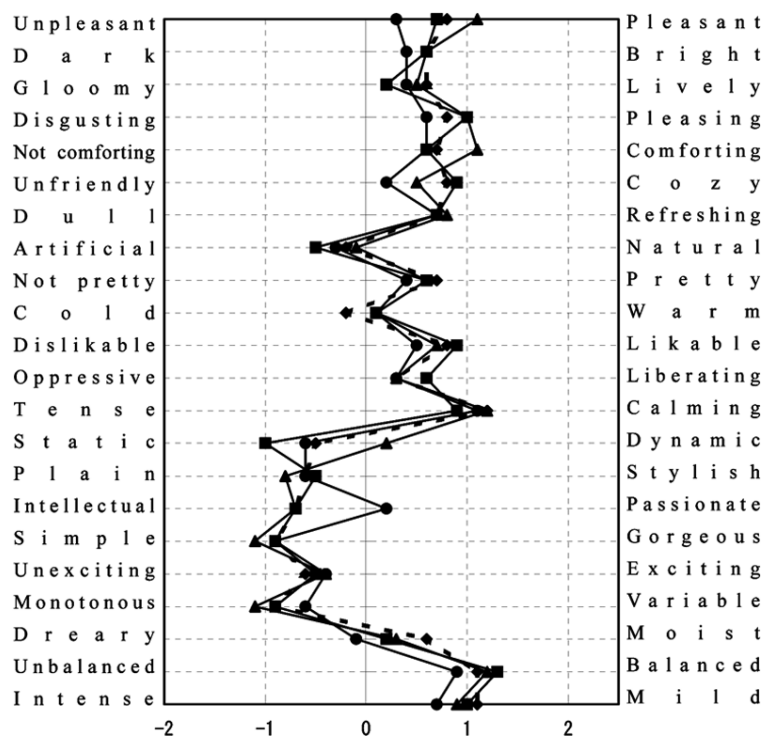

Fig. 4 Change in the image profiles of cactus evaluated by the elderly people.

$\boldsymbol{\square}, \boldsymbol{\Delta}$, and $\boldsymbol{\nabla}$ indicate the starting week, second week, sixth week, and tenth week, respectively.

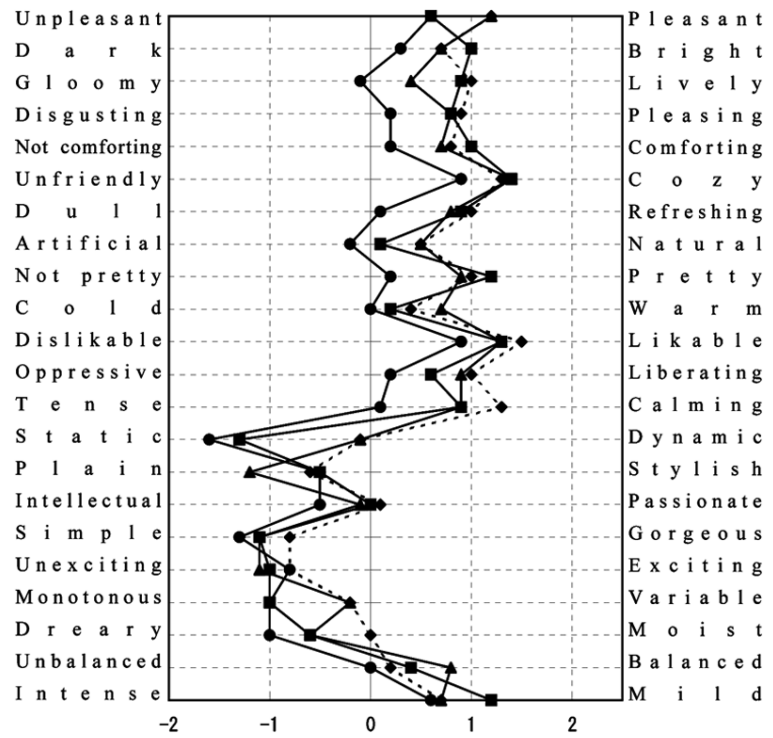

Fig. 5 Change in the image profiles of cactus evaluated by the young people.

The symbols $(\boldsymbol{\sim}, \boldsymbol{\square}, \boldsymbol{\Delta}$, and $\boldsymbol{\nabla})$ are the same as those in Fig. 4.

around the sixth week, values centered around the second factor ("visual attractiveness") increased in both young and elderly subjects. These changes were similar to EEG findings.

Figures 9 and 10 show the changes in factor score distribution for each plant in elderly and young subjects. Factor scores for the four plant species in young subjects were distributed apart from each other, indicating differences in psychological state depending on the type of plant. As 


\section{S. NORIMATSU ET AL.}

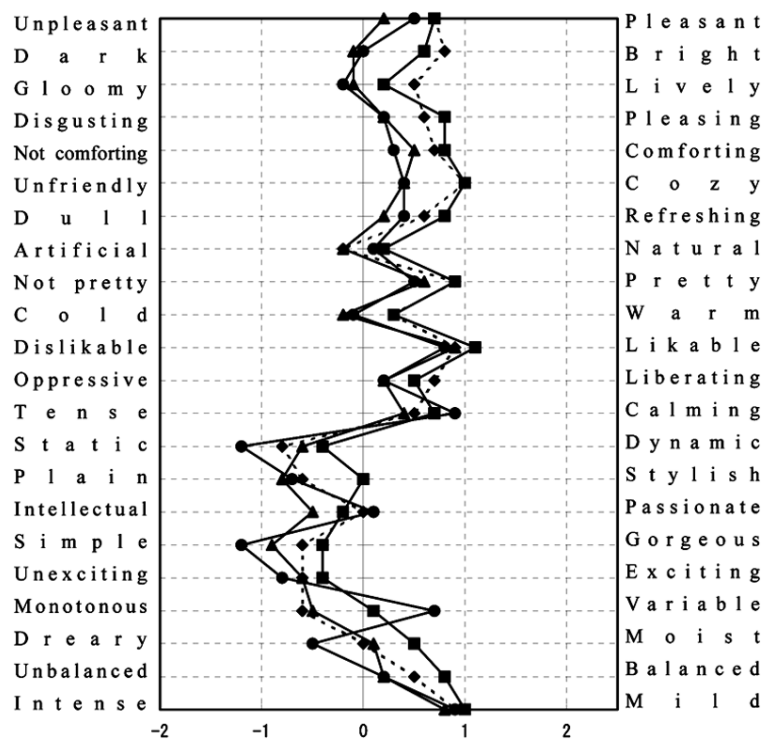

Fig. 6 Change in the image profiles of hyacinth evaluated by the elderly people. The symbols $(\boldsymbol{O}, \mathbf{\square}, \mathbf{\Delta}$, and $\boldsymbol{\nabla}$ ) are the same as those in Fig. 4.

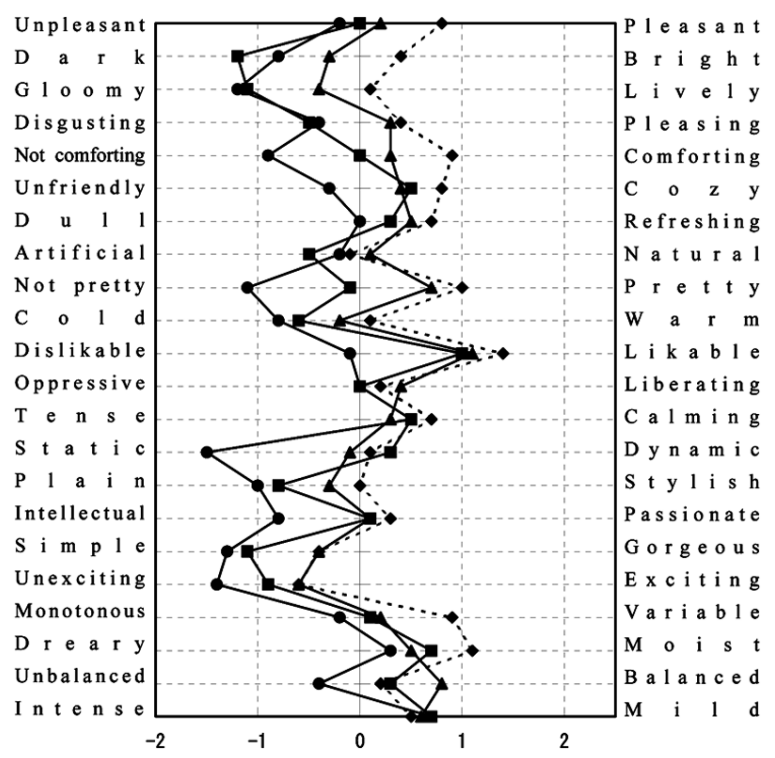

Fig. 7 Change in the image profiles of hyacinth evaluated by the young people.

The symbols $(\boldsymbol{O}, \mathbf{\square}$, and $\boldsymbol{\nabla})$ are the same as those in Fig. 4.

for temporal changes, the first factors for hyacinth and cactus increased significantly during the 10week study. In contrast, factor scores for the four plant species in elderly subjects were distributed relatively close to each other, and showed fewer temporal changes for each plant. However, the second factor for the pansy increased significantly during the 10 -week study. This result was the same as the EEG findings. 


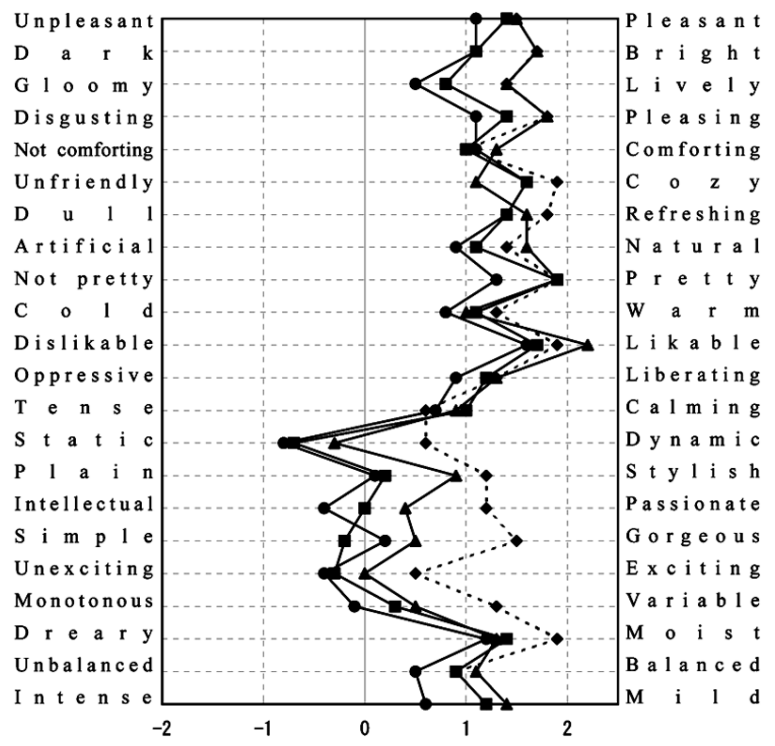

Fig. 8 Change in the image profiles of pansy evaluated by the elderly people. The symbols $(\boldsymbol{\sim}, \boldsymbol{\square}, \boldsymbol{\Delta}$, and $\boldsymbol{\nabla})$ are the same as those in Fig. 4.

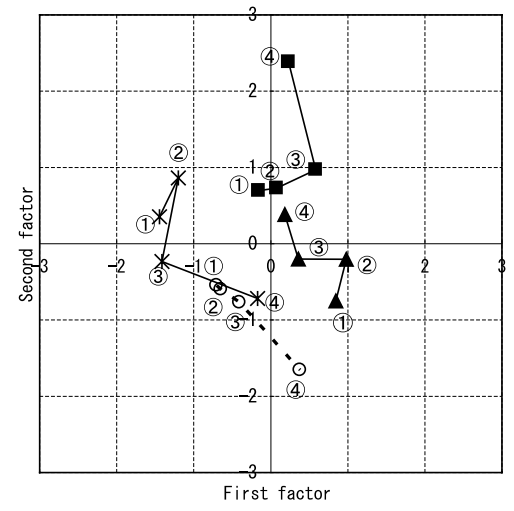

Fig. 9 A factor score change figure of the four plants evaluated by the elderly people in ten weeks. The symbols ( $*, \mathbf{\square}, \mathbf{\Delta}$, and $\bigcirc$ ) are the same as those in Fig. 2.

(1) (4) indicate the starting week, second week, sixth week, and tenth week, respectively.

Because the changes in mean value profile of elderly subjects were smaller than those of young subjects with respect to the cactus (a plant that does not change morphologically), hyacinth (a bulbous and hydroponically grown plant that develops roots), and pansy (a plant that develops from a seedling to a budded and blooming plant), changes in the psychological state of elderly individuals were not thought to be greatly affected by changes in plant morphology.

However, because increases in scores for the second factor ("visual attractiveness") for the pansy, which bloomed during its growth process, were observed in elderly subjects as well, it was surmised that the blooming of the plants affected the psychological state of elderly individuals. In our previous study (Norimatsu et al., 2006), changes in the psychological state of elderly subjects were not observed for cyclamen, a plant that was already blooming at the start of the study. Thus, 


\section{S. NORIMATSU ET AL.}

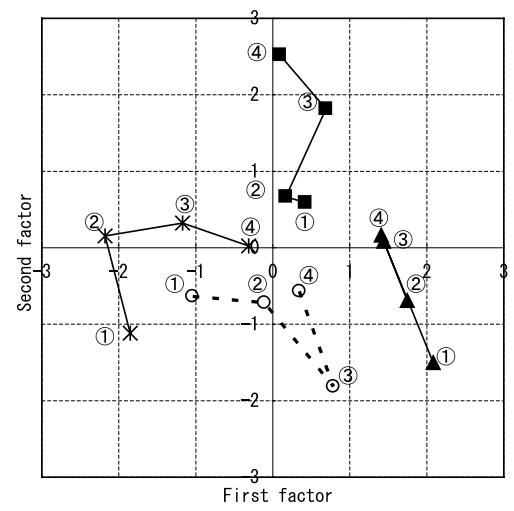

Fig. 10 A factor score change figure of the four plants evaluated by the young people in ten weeks. The symbols ( $*, \mathbf{\square}, \mathbf{\Delta}$, and $\bigcirc$ ) are the same as those in Fig. 2. The symbols (1) (4) are the same as those in Fig. 9.

the psychological state of elderly individuals was thought to change in response to the process of plants budding and blooming from a seedling, rather than to the actual state of blooming.

\section{AFTERWORD}

The present study confirmed the finding that horticultural therapy helps stabilize the psychological state of elderly individuals through the process of raising plants itself, regardless of the type of plant or morphological changes. In addition, because the psychological state of elderly individuals was thought to change with respect to "attractiveness" in response to the process of plants budding and blooming from a seedling, rather than to the actual state of blooming, horticultural therapy using flowering plants that can be raised from a seedling or bulb was thought to be optimal for inducing psychological effects in elderly individuals, who may be at an increased risk for depression.

We express our gratitude to the study participants for their time and cooperation.

\section{REFERENCES}

Asaumi, H., Nishina, H., Masui, N., Hashimoto, Y. 1993. Measurement of transpiration rate, stomatal resistance, and shading ratio of "amenity plants" (in Japanese with English abstract). J. Soc. High Tech. Agric. 4: 131-138.

Asaumi, H., Nishina, H., Nakamura, H., Masui, N., Hashimoto, Y. 1995a. Effect of ornamental foliage plants on visual fatigue caused by visual display terminal operation (in Japanese with English abstract). J. Soc. High Tech. Agric. 7: 138-143.

Asaumi, H., Nishina, H., Namba, R., Masui, N., Hashimoto, Y. 1995b. Evaluation of impression of ornamental foliage plants and psychological rating of rooms with ornamental foliage plants by means of semantic differential method (in Japanese with English abstract). J. Soc. High Tech. Agric. 7: 34-45.

Asaumi, H., Nishina, H., Tsukanishi, K., Masui, N., Hashimoto, Y. $1994 . \quad$ Effects of foliage plants on thermal environment and comfort inside room - Experimental analysis in winter - (in Japanese with English abstract). J Archit. Plann. Environ. Eng., AIJ 464: 39-46.

Funakoshi, T. 1987. Semantic differential technique. In "Survey and Analysis Method for Architectural and Town Planning” (ed. by Architectural Institute of Japan) (in Japanese). Inouesyoin, Tokyo, p 65-70.

Grosse, S. 2000. Horticultural therapy - Healing mind and body by contact with plants (in Japanese). Japan 


\section{PSYCHOLOGICAL EFFECT OF RAISING PLANT}

Institute for Community Affairs, Tokyo, p1-268.

Iwashita, T. 1983. Measurement of images by means of semantic differential technique (in Japanese). Kawashimasyoten, Tokyo, pp 204.

Kato, K., Mochizuki, N., Yamazaki, K., Kobayashi, K. 2004. Study on physiological effect of fire based on EEG measurement (in Japanese). Summaries of Technical Papers of Annual Meeting 2004, Architectural Institute of Japan: 927-928.

Matsuo, E. 2000. Survey of horticultural therapy - In search for healing and humanity - (in Japanese). Green Joho, Nagoya, p1-305.

Nakajima, K. 2005. Change by aging. In "Elderly Nursing” (in Japanese). Igakusyoin, Tokyo, p18-34.

Nishina, H. 2000. Studies on green amenity (in Japanese). Environ. Control Biol. 38: 285-290.

Nishina, H., Gouda, C. 2004. Analysis of influence of liking for plants and raising plants on human psychology (in Japanese). Proc. Joint Meeting on Environmental Engineering in Agriculture 2004: 181.

Nishina, H., Kawanishi, T. 1999. Effects of ornamental foliage plants on thermal environment and comfort inside room - Experimental analysis in spring and summer - (in Japanese with English abstract). Environ. Control Biol. 37: 73-81.

Nishina, H., Nagayasu, M. 2002. An approach to horticultural therapy from standpoint of green amenity Analysis of attachment for plant in taking care of plant - (in Japanese). Proc. Joint Meeting on Environmental Engineering in Agriculture 2002: 170.

Nishina, H., Nakamoto, Y. 1998. Analysis of amenity effect of plants and fragrance on human physiology and psychology by means of brain waves and semantic differential technique (in Japanese with English abstract). J Archit. Plann. Environ. Eng., Transaction of AIJ. 509: 71-75.

Nishina, H., Nakamoto, Y., Watamori, S., Masui, N., Hashimoto, Y. 1998. Analysis of amenity effect of ornamental foliage plants on human psychology by means of brain waves and semantic differential technique (in Japanese with English abstract). J. Soc. High Tech. Agric. 10: 65-69.

Nishina, H., Nakamura, H., Asaumi, H., Masui, N., Hashimoto, Y. 1995. Simulation model of thermal environment and comfort in rooms where plants are placed (in Japanese with English abstract). Environ. Control Biol. 33: 277-284.

Norimatsu, S., Nishina, H., Iekushi, K. 2006. Analysis of psychological states of elderly people in process of raising plants by means of brain waves an semantic differential technique - Including comparison with young people - (in Japanese with English abstract). J SHITA 18: 97-104.

Tsumita, H. 1987. Analysis of factor, Quantity theory type III. In "Survey and Analysis Method for Architectural and Town Planning" (ed. by Architectural Institute of Japan) (in Japanese). Inouesyoin, Tokyo, p135-141.

Uchida, M., Yamazaki, M., Choi, J., Yamazaki, K., Hotta, K. 2004. A study on the physiological effect of sounds including ultrasonic waves (in Japanese). Summaries of Technical Papers of Annual Meeting 2004, Architectural Institute of Japan: 95-96.

Yamazaki, M., Okamoto, Y., Yamazaki, K., Choi, J., Hotta, K. 2003. A study of the practicality of artificial high sound that referenced the sound of waves (in Japanese). Summaries of Technical Papers of Annual Meeting 2003, Architectural Institute of Japan: 227-228.

Yoshinaga, M., Shioya, T., Kondou, T. 1998. Recommendation of horticultural therapy (in Japanese). Soshinsha, Tokyo, p1-301. 